\title{
Molecular and clinical examination of an Italian DEFECT 11 family
}

\author{
Wim Wuyts ${ }^{1}$, Giancarlo Di Gennaro ${ }^{2}$, Federico Bianco ${ }^{2}$, Jan Wauters ${ }^{1}$, \\ Cristoforo Morocutti ${ }^{3}$, Francesco Pierelli ${ }^{2}$, Paul Bossuyt ${ }^{1}$, Wim Van Hul $^{1}$ and \\ Carlo Casali $^{2}$ \\ ${ }^{1}$ Department of Medical Genetics, University of Antwerp, Antwerp, Belgium \\ ${ }^{2}$ Neurological Institute 'La Sapienza' University, Rome, Italy \\ ${ }^{3}$ Istituto Neurologico Mediterraneo di Neuroscienze, NEUROMED, Pozzilli, Isernia, Italy
}

\begin{abstract}
The DEFECT 11 syndrome is a contiguous gene syndrome associated with deletions in the proximal part of chromosome 11p. In this study, we describe in an Italian family the co-existence of multiple exostoses (EXT) and enlarged parietal foramina (FPP), the two major symptoms of this syndrome, with abnormalities of the central nervous system. The latter may be a yet undescribed feature of DEFECT 11 syndrome. FISH and molecular analysis allowed us to identify a small deletion on 11p11-p12, further refining the localisation of the FPP gene involved in the DEFECT 11 syndrome.
\end{abstract}

Keywords: DEFECT 11; multiple exostoses; FPP; chromosome 11; deletion; brain abnormalities

\section{Introduction}

To date, only 11 patients suffering from DEFECT 11 syndrome, a contiguous gene syndrome caused by deletions in the proximal part of the short arm of chromosome 11 have been described. ${ }^{1-7}$ The DEFECT 11 syndrome presents a characteristic clinical spectrum, the most typical features being multiple exostoses (EXT) and Foramina Parietalia Permagna (FPP), while mental retardation and craniofacial abnormalities are often also observed. ${ }^{6}$

Exostoses are bony protuberances which are found on the long bones. ${ }^{8}$ In addition to the DEFECT 11 syndrome, these benign bone tumours can also be found in another contiguous gene syndrome, the

Correspondence: Wim Wuyts, PhD, Department of Medical Genetics, University of Antwerp, Universiteitsplein 1, 2610 Antwerp, Belgium. Fax: 32382025 66; Tel: 3238202630 ; E-mail: wwuyts@uia.ua.ac.be

Received 20 November 1998; revised 16 February 1999; accepted 22 February 1999
Langer-Giedion syndrome (LGS) ${ }^{9}$ or they can be present as an isolated autosomal dominant condition. In approximately $2-5 \%$ of the patients, malignant transformation of an exostosis occurs, resulting in the development of a chondrosarcoma ${ }^{10,11}$ So far two $E X T$ genes have already been identified, EXT1 on chromosome $8 \mathrm{q} 24^{12}$ and $E X T 2$ on chromosome 11p11-p12, ${ }^{13,14}$ while a third locus, EXT3, has been mapped on chromosome 19 p. ${ }^{15}$ The $E X T$ genes are members of a larger family of homologous genes which also currently includes three EXT-like genes - EXTL1, ${ }^{16}$ EXTL2 $2^{17}$ and EXTL3. ${ }^{18}$ Recently it has been shown that the EXT1 and EXT2 genes are glycosyltransferases required for the biosynthesis of heparan sulfate. ${ }^{19,20}$ The recent identification of the tout-velu (ttv) gene, the Drosophila homologue of the EXT1 gene which is essential for proper diffusion of the Drosophila hedgehog $(\mathrm{Hh})$ protein, ${ }^{21}$ suggests that EXT1 is probably involved in the synthesis of a GAG that specifically interacts with $\mathrm{Hh}$ protein at the cell surface. 
Foramina parietalia permagna, also called the Catlin mark, ${ }^{22}$ is a cranial ossification defect located mostly symmetrically on both sides of the sagittal suture. The openings decrease in size with time and show great variability, even within one family, but they can be clearly distinguished from normal small foramina of a few millimeters. ${ }^{23}$ Reduced penetrance of FPP has been described, both in DEFECT 11 patients ${ }^{6}$ and in patients affected with the isolated autosomal dominant form of FPP. $^{22}$

Besides EXT and FPP, other clinical symptoms of DEFECT 11 syndrome, including mental retardation, micropenis and craniofacial abnormalities, have been reported. However, these features are not found in all the patients described, and they seem to be associated with larger deletions around the EXT2 gene. ${ }^{6}$

In this paper we report on the clinical and molecular analysis of a family with DEFECT 11 syndrome and additional brain abnormalities.

\section{Materials and Methods}

\section{Cytogenetical Analysis}

Chromosomes were obtained from phytohaemagglutinin blood cultures using trypsin (GTG) banding according to standard protocols. As the 550-band resolution did not show any abnormality, the chromosome length was increased to obtain an 850-band karyotype.

\section{Molecular Analysis}

PCR analysis was performed with the polymorphic markers

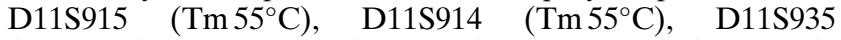
$\left(\mathrm{Tm} 55^{\circ} \mathrm{C}\right), \mathrm{D} 11 \mathrm{~S} 1355\left(\mathrm{Tm} 57^{\circ} \mathrm{C}\right), \mathrm{D} 11 \mathrm{~S} 1785 \quad\left(\mathrm{Tm} 55^{\circ} \mathrm{C}\right)$, $\mathrm{D} 11 \mathrm{~S} 1393 \quad\left(\mathrm{Tm} 55^{\circ} \mathrm{C}\right), \quad \mathrm{D} 11 \mathrm{~S} 903 \quad\left(\mathrm{Tm} 57^{\circ} \mathrm{C}\right), \quad \mathrm{D} 11 \mathrm{~S} 2095$ $\left(\mathrm{Tm} 55^{\circ} \mathrm{C}\right), \mathrm{D} 11 \mathrm{~S} 554\left(\mathrm{Tm} 58^{\circ} \mathrm{C}\right)$ and $\mathrm{D} 11 \mathrm{~S} 1319\left(\mathrm{Tm} 55^{\circ} \mathrm{C}\right)$. The position of these markers was obtained from the Généthon linkage map ${ }^{24}$ and a detailed map of the EXT2 region published by Wuyts et al. ${ }^{14}$

\section{FISH}

Fluorescence in situ hybridisation was performed as described previously $^{25}$ with the EXT2 cDNA probe yf69b06, P1 clones ICRFP700M1637 (D11S578) and ICRFP700O1366 (D11S1393) and cosmids cCI11-540 (D11S2095) and cCI11388 (D11S554). All probes were previously mapped to the pericentromeric region of chromosome $11 .^{14}$

\section{Results}

\section{Clinical Analysis}

A 19-year-old man was referred for recurrent, brief seizures characterised by sudden dizziness followed by motor arrest, loss of contact and short-lived postictal confusion, symptoms he had suffered from the age of 14. Physical examination was remarkable for large parietal bone defects (FPP), which were confirmed on skull X-rays (Figure 1A). X-rays of extremities disclosed multiple exostoses (EXT) in the juxta-epiphyseal region of the long bones of the limbs and a deformity of the forearm (Figure 1B). EEG showed a normal background rhythm and frequent, pseudoperiodic, di-triphasic sharp waves over the left parietal region. On CT (Figure 2A) and MRI (Figure 2B), hypoplasia of the medial aspect of the occipital lobes with corresponding enlargement of the posterior interhemispherical space, mild hypoplasia of the vermis and cerebellar hemispheres as well as abnormal insertion of the posterior free margin of the cerebellar tentorium was observed. On closer investigation the proband's brother (IV2), his father (III1) and grandfather (II2) were also found to be affected by FPP and EXT (Figure 3). Brain CT scan, only performed in subjects III1 and IV1, showed similar abnormalities of posterior fossa, although to a lesser degree. Craniofacial appearance was normal in all subjects and none of the patients showed mental retardation. None of the propositus' relatives had presented seizures or any neurological abnormalities and their EEG was normal.

\section{Cytogenetical Analysis}

Analysis of the GTG banded chromosomes of the proband and his father at the 550-band level did not show any chromosomal abnormality. To detect a possible small deletion, the resolution was increased to the 850-band level, but again a normal karyotype was observed.

\section{Molecular Analysis}

PCR analysis showed a deletion on the paternal chromosome of markers D11S903 and D11S2095 in the proband and his affected brother. Also the father and grandfather showed only one allele for these markers, probably due to hemizygosity. Several markers located distal of D11S903 were analysed to define the distal deletion breakpoint. Both proband and brother were heterozygous for markers D11S915, D11S914, D11S1355, D11S1785 and D11S1393, while D11S935 was not informative. Proximal of D11S2095, D11S554 and D11S1319 were not deleted (Figure 3).

\section{FISH}

FISH analysis showed deletion of probes yf69b06 (EXT2) and cCI11-540 (D11S2095). Two copies were found for P1 clone ICRFP700M1637, which is located between D11S1355 and D11S1393 and for P1 clone 
A

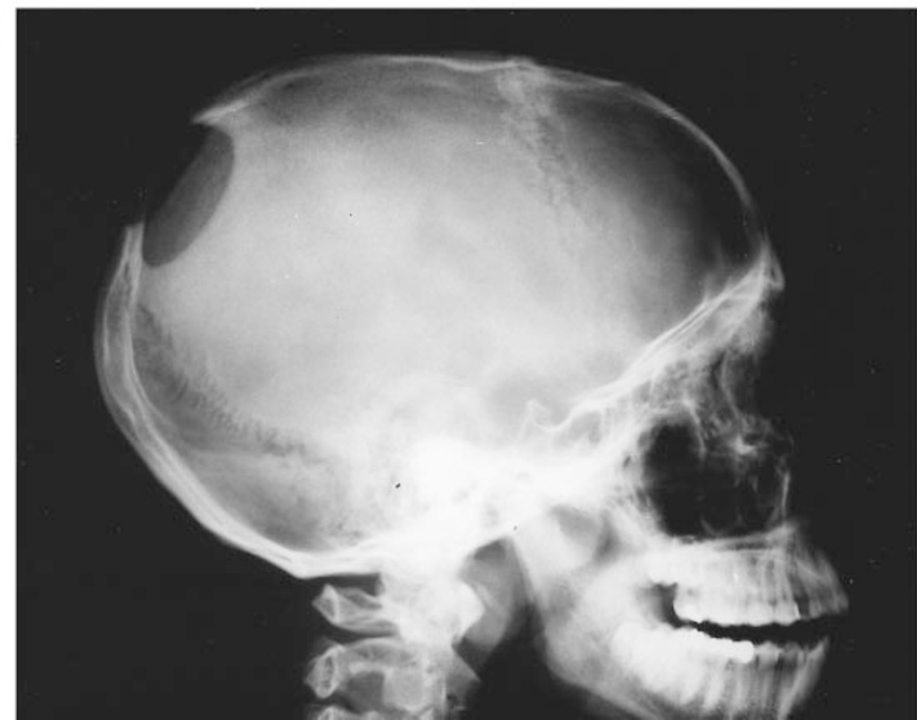

B

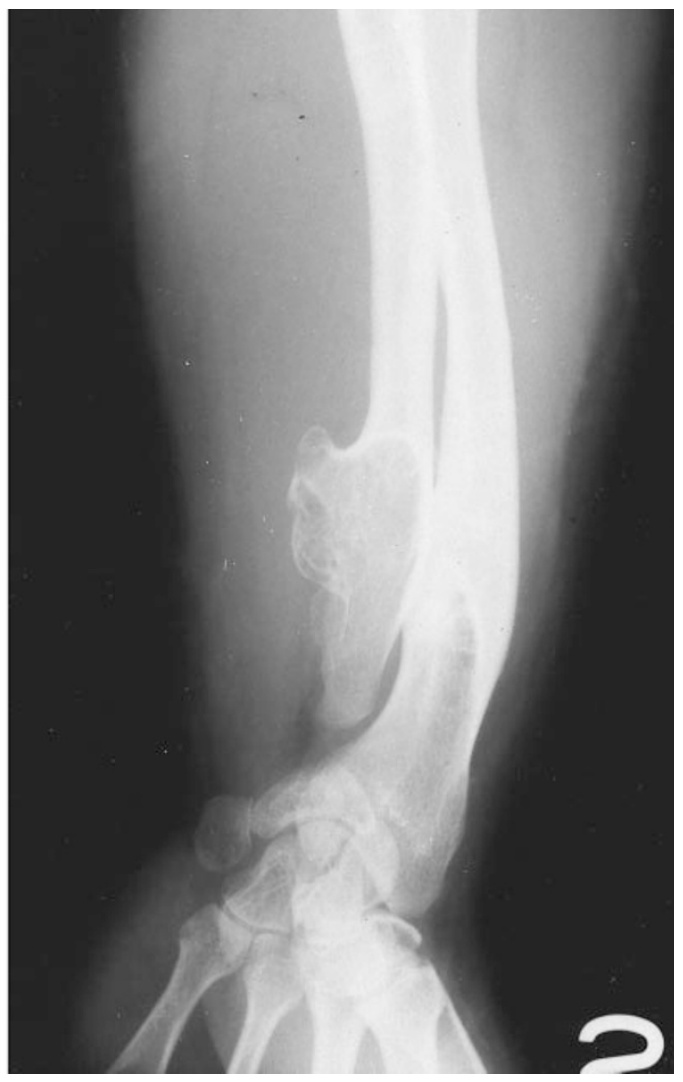

Figure 1 X-rays of the proband, showing foramina parietalia permagna (A) and multiple exostoses with distal deformity of the radius and ulna $(\mathbf{B})$.

A

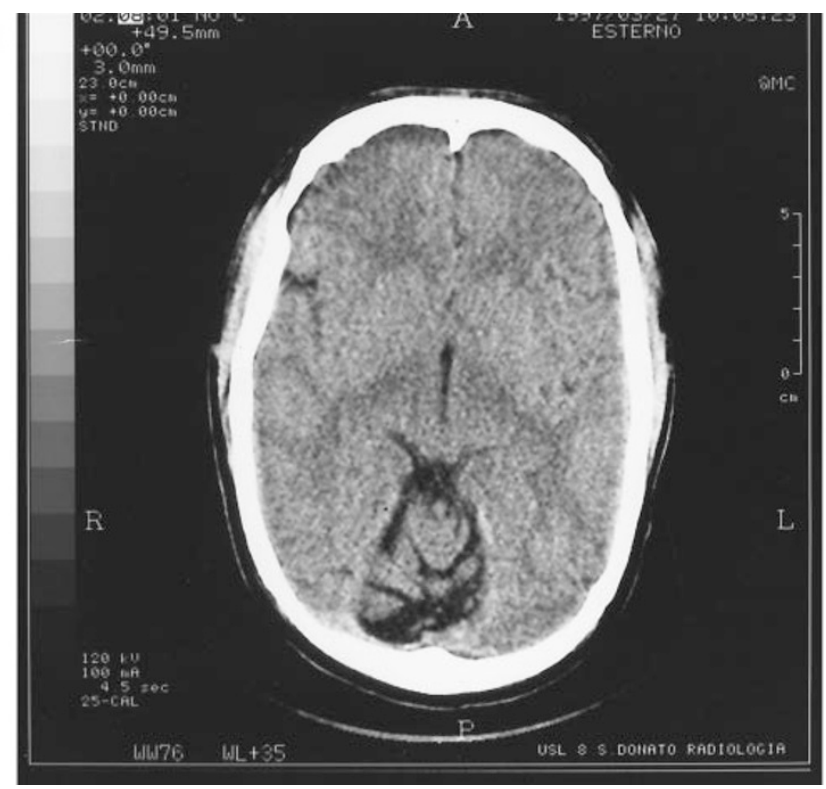

B

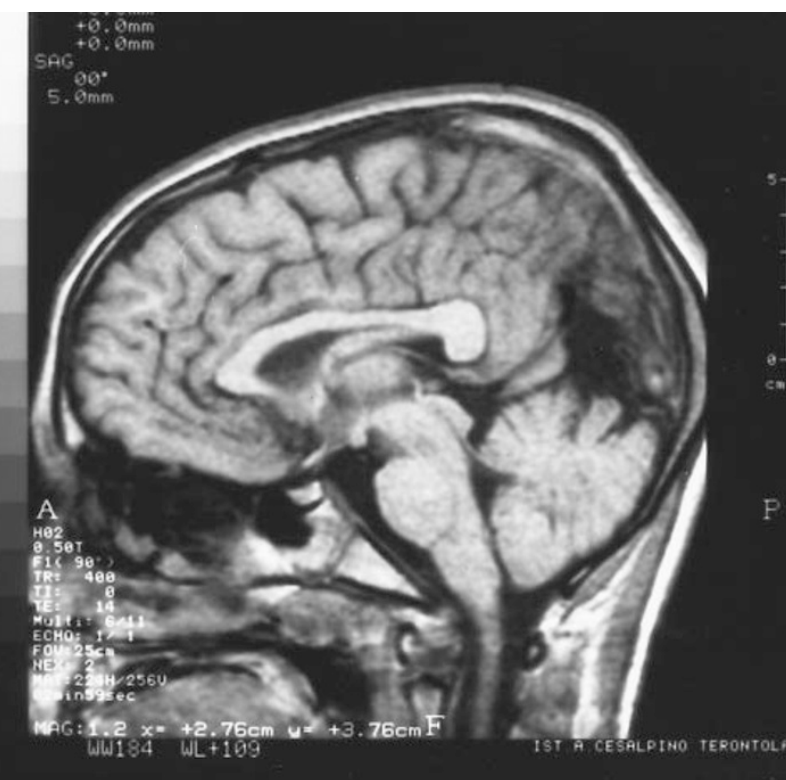

Figure 2 Brain CT (A) and MRI (B) scan of the proband, showing hypoplasia of the medial aspect of the occipital lobes, enlargement of the posterior interhemispherical space, mild hypoplasia of the vermis and cerebellar hemispheres and abnormal insertion of the posterior free margin of the cerebellar tentorium. 
ICRFP70001366 (D11S1393). Also cosmid cCI11-388 (D11S554) was not deleted.

\section{Discussion}

So far, only 11 patients suffering from DEFECT 11 syndrome have been reported. ${ }^{6}$ Here we report on four patients from three generations of an Italian family showing the co-existence of multiple exostoses and enlarged parietal foramina, two of the major symptoms of this syndrome. To confirm the diagnosis of DEFECT 11 syndrome, karyotyping was performed on GTG banded chromosomes but even at the 850-band resolution a normal karyotype was observed. However, as shown before, the extent of the deletion and the

\section{A}

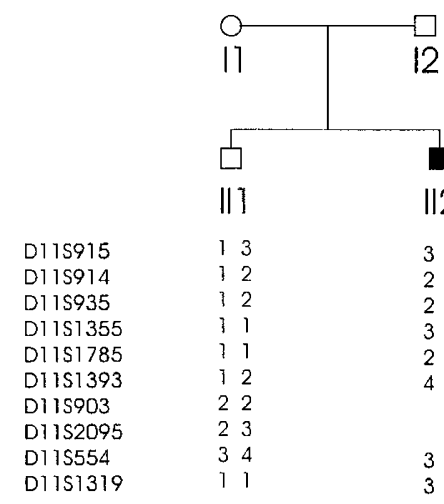

B

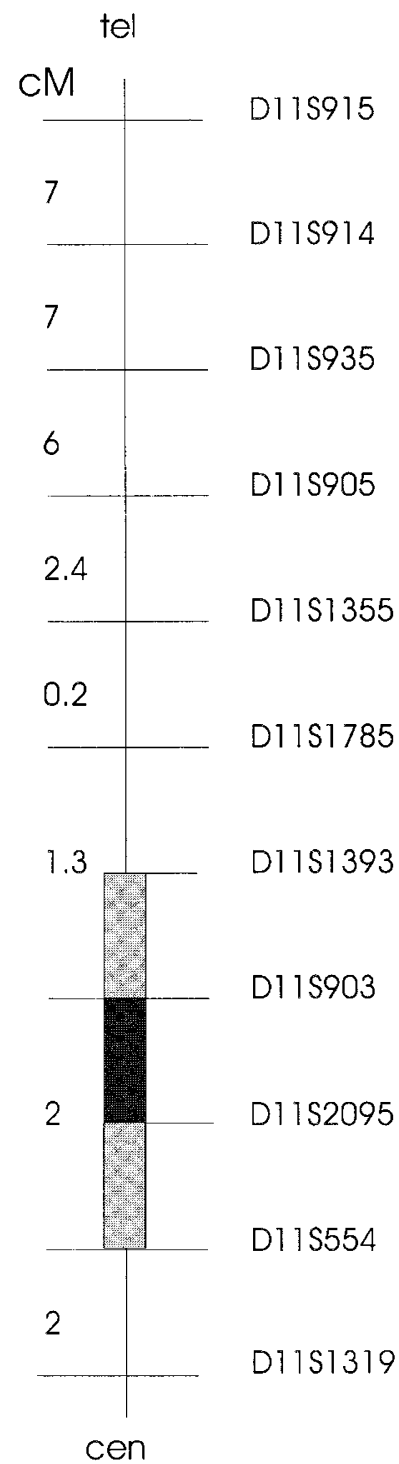

Figure 3 Molecular analysis of chromosome 11 markers. A Results of the PCR analysis of chromosome 11 markers show the segregation of a deletion between markers D11S1393 and D11S554 in this family. The proband is indicated by an arrow. B Position of the deletion is represented with respect to the regions containing genes responsible for the main symptoms of DEFECT 11 syndrome (white boxes), being Enlarged Foramina (FPP), multiple Exostoses (EXT), Craniofacial dysotosis (CD) and mental reTardation $(M R)$. Delineation of these regions was based upon correlation between deletion interval and phenotype in various DEFECT 11 patients described in this and previous studies. ${ }^{5,6,14}$ The black box indicates the deletion in the Italian DEFECT 11 family, whilst distal and proximal regions containing the deletion breakpoints are grey. Distances between the various markers are represented in centimorgans $(c M)$. 
position of the deletion breakpoints are highly variable between the several DEFECT11 patients. Previously, Bartsch $e t a l^{6}$ also reported the absence of chromosomal abnormalities at the 250 band and at higher resolution, especially in those DEFECT 11 patients with a milder clinical phenotype. Since the clinical spectrum of our patients did not include mental retardation, craniofacial abnormalities or micropenis, the symptoms that seem to be associated with a larger $11 \mathrm{p}$ deletion (Figure 3), a small deletion around the EXT2 gene, seemed more likely. Molecular analysis indeed showed a deletion between D11S1393 and D11S554, a region of approximately $3 \mathrm{cM} .{ }^{14}$ The extent of the deletion was confirmed by FISH with probes located in the EXT2 region on chromosome 11p11-p12 (data not shown). Previously, the EXT2 gene has been shown to fall in this interval, whilst for the FPP gene a localisation between D11S1355, located distal of D11S1393, and D11S2095, mapped distal of D11S554, has been defined. ${ }^{6,14}$ Therefore, these results refine the possible localisation of the FPP gene on chromosome 11 to a region between the markers D11S1393 and D11S2095.

Interestingly, EXT and FPP are accompanied by epilepsy and posterior cerebral fossa abnormalities in the proband. The association between FPP and seizures has been reported previously, ${ }^{26}$ also in patients suffering from DEFECT 11 syndrome ${ }^{6}$ and possibly epilepsy may be a consequence of FPP. This hypothesis is corroborated by the fact that the parietal epileptic focus in the proband is located immediately below the left parietal bone defect. However, it must be noted that association of both symptoms is not complete, as demonstrated by the fact that the other patients of this family did not suffer from epilepsy and their EEG was normal. The complex malformation of the cerebral structures localised in the posterior cerebral fossa co-segregates with the deletion in all the patients, suggesting that this anomaly may be part of the DEFECT 11 syndrome. A similar defect has never been described in previously reported DEFECT 11 patients, ${ }^{6}$ but this might be due to the fact that these patients were probably never examined by CT and/or MRI. Re-examination of one DEFECT 11 patient with a previous reported deletion between D11S915 and D11S2095 ${ }^{14}$ was performed, but did not reveal any brain abnormality (J McGaughran, personal communication). As the deletion in our family extends centromeric of D11S2095, the malformation of the cerebral structures might therefore be associated with a deletion in this region. However, DEFECT 11 patients with deletions comprising the entire deletion interval of our family will have to be re-examined to clarify whether the brain abnormalities are a true symptom of DEFECT 11 syndrome.

In conclusion, we report on four new patients with DEFECT 11 syndrome, extending the total number of published DEFECT11 patients to 15. Clinically, we describe the previously unreported association of EXT and FPP with structural brain abnormalities. Finally, molecular analysis resulted in a further molecular characterisation of this syndrome, with a refined position of the FPP gene involved in this syndrome.

\section{Acknowledgements}

WW is a postdoctoral researcher of the Fund for Scientific Research, Flanders (FWO). This study was supported by a concerted-action grant from the University of Antwerp to WVH.

\section{References}

1 Gustavson HH, Annerén G, Wranne L: Two cases of 11 p13 interstitial deletion and unusual clinical features. Clin Genet 1984; 26: 247-249.

2 Lorenz P, Rupprecht E, Tellkamp H: An unusual type of acrocephalosyndactyly with bilateral parietooccipital encephalocele, micropenis and severe mental retardation. Am J Med Genet 1990; 36: 265-268.

3 Shaffer LG, Hecht JT, Ledbetter DH, Greenberg F: Familial interstitial deletion 11(p11.12p12) associated with parietal foramina, brachymicrocephaly and mental retardation. Am J Med Genet 1993; 45: 581-583.

4 McGaughran JM, Ward HB, Evans DGR: WAGR syndrome and multiple exostoses in a patient with $\operatorname{del}(11)(\mathrm{p} 11.2 \mathrm{p} 14.2)$. Am J Med Genet 1995; 32: 823-824.

5 Potocki L, Greenberg F, Shaffer LG: Interstitial deletion of 11(p11.12p12): a rare chromosomal syndrome with mental retardation, parietal foramina and multiple exostoses. Am J Hum Genet 1995; 57 (Suppl): 688.

6 Bartsch O, Wuyts W, Van Hul W et al: Delineation of a contiguous gene syndrome with multiple exostoses, enlarged parietal foramina, craniofacial dysotosis and mental retardation, caused by deletions on the short arm of chromosome 11. Am J Hum Genet 1996; 58: 734-742.

7 Ligon A, Potocki L, Shaffer LG, Stickens D, Evans GA: Gene for multiple exostoses (EXT2) maps to 11(p11.2p12) and is deleted in patients with a contiguous gene syndrome. Am J Med Genet 1998; 75: 538-540.

8 Solomon L: Bone growth in diaphyseal aclasis. $J$ Bone Joint Surg 1961; 43: 700-716.

9 Langer LO, Krassikoff N, Laxova R et al: The trichorhinophalangeal syndrome with exostoses (or Langer-Giedion syndrome): four additional patients without mental retardation and review of the literature. Am J Med Genet 1984; 19: 81-111. 
10 Jaffe HL: Hereditary multiple exostoses. Arch Pathol 1943; 36: 335-357.

11 Wicklund CL, Pauli RM, Johnston D, Hecht JT: Natural history study of hereditary multiple exostoses. Am J Med Genet 1995; 55: 43-46.

12 Ahn J, Lüdecke H, Lindow S et al: Cloning of the putative tumour suppressor gene for hereditary multiple exostoses (EXT1). Nat Genet 1995; 11: 137-143.

13 Stickens D, Clines G, Burbee D et al: The EXT2 multiple exostoses gene defines a family of putative tumour suppressor genes. Nat Genet 1996; 14: 25-32.

14 Wuyts W, Van Hul W, Wauters J et al: Positional cloning of a gene involved in hereditary multiple exostoses. Hum Mol Genet 1996; 5: 1547-1557.

15 Le Merrer M, Legeai-Mallet L, Jeannin PM et al: A gene for hereditary multiple exostoses maps to chromosome 19p. Hum Mol Genet 1994; 3: 717-722.

16 Wise CA, Clines GA, Massa H, Trask BJ, Lovett M: Identification and localization of the gene for EXTL, a third member of the multiple exostoses gene family. Genome Res 1997; 7: 10-16.

17 Wuyts W, Van Hul W, Hendrickx $\mathrm{J}$ et al: Identification and characterization of a novel member of the EXT gene family, EXTL2. Eur J Hum Genet 1997; 5: 382-389.

18 Van Hul W, Wuyts W, Hendrickx J et al: Identification of a third EXT-like gene (EXTL3) belonging to the EXT gene family. Genomics 1998; 47: 230-237.
19 McCormick C, Leduc Y, Martindale D et al: The putative tumour suppressor EXT1 alters the expression of cellsurface heparan sulfate. Nat Genet 1998; 19: 158-161.

20 Lind T, Tufaro F, McCormick C, Lindahl U, Lidholt K: The putative tumor suppressors EXT1 and EXT2 are glycosyltransferases required for the biosynthesis of heparan sulfate. J Biol Chem 1998; 273: 26265-26268.

21 Beilaiche Y, The I, Perrimon N: Tout-velu is a Drosophila homologue of the putative tumour suppressor EXT-1 and is needed for Hh diffusion. Nature 1998; 394: 85-88.

22 Goldsmith WM: The Catlin mark: the inheritance of an unusual opening in the parietal bones. J Heredity 1922; 13: 69-71.

23 Murphy J, Gooding CA: Evolution of persistently enlarged parietal foramina. Radiology 1970; 97: 391-392.

24 Dib C, Fauré S, Fizames C et al: A comprehensive genetic map of the human genome based on 5264 microsatellites. Nature 1996; 380: 152-154.

25 Wauters JG, Bossuyt PJ, Davidson J, Hendrickx J, Kilimann MW, Willems PW: Regional mapping of a liver a-subunit gene of phosphorylase kinase (PHKA) to the distal region of human chromosome Xp. Cytogenet Cell Genet 1992; 60: 194-196.

26 Kite WC Jr: Seizures associated with the Catlin mark. Neurology 1961; 11: 345-348. 